\title{
ИСПОЛЬЗОВАНИЕ ЭТНОПЕДАГОГИЧЕСКОГО ПОТЕНЦИАЛА РЕГИОНА В ФОРМИРОВАНИИ ГРАЖДАНСКОЙ ИДЕНТИЧНОСТИ СТУДЕНТОВ
}

\section{USING THE ETHNOPEDAGOGICAL POTENTIAL OF THE REGION IN THE FORMATION OF STUDENTS' CIVIC IDENTITY}

\section{Savinova \\ M. Khasanova}

Summary: The article gives the author's interpretation of the definition of the concept of "ethnopedic-gogic potential of the region": essential characteristics, structural components. The possibilities of using the ethnopedagogical potential of the region in the process of forming civic identity of students of a classical university are determined. The experience of the formation of the studied personality traits in the context of the implementation of a specific project is presented.

Keywords: civic identity, ethnopedagogical potential of the region, mentality of the nation, national traditions, regional cultural values, spatial localization, project.
Савинова Людмила Федоровна

Д.п.н., профессор, ФГБОУВО «Карачаево-Черкесский государственный университет имени У.Д. Алиева»

savinova.If@mail.ru

Хасанова Марина Османовна

Аспирант, ФГБОУ ВО «Карачаево-Черкесский университет имени У.Д. Алиева»

marina.khasanova@mail.ru

Аннотация: В статье даётся авторская трактовка определения понятия «этнопедагогический потенциал региона»: сущностные характеристики, структурные компоненты. Определены возможности использования этнопедагогического потенциала региона в процессе формирования гражданской идентичности студентов классического университета. Представлен опыт формирования исследуемых качеств личности в условиях реализации конкретного проекта.

Ключевые слова: гражданская идентичность, этнопедагогический потенциал региона, менталитет нации, национальные традиции, региональные ценности культуры, пространственная локализация, проект.
Ц ель статьи: показать возможности использования этнопедагогического потенциала региона в процессе формирования гражданской идентичности студентов.

Проблема формирования гражданской идентичности студентов заслуживает самого пристального внимания, так как, по сути, речь идёт о завтрашнем дне России, её национальной безопасности. На эту особенность обращают внимание учёные. И.В. Кожанов, Н.П. Петрова в своём исследовании подчёркивают, что сформированная гражданская идентичность способствует «не просто укреплению единства многонационального народа Российской Федерации (российской нации) через формирование и развитие общероссийского гражданского патриотизма и солидарности, но и сохранению этнокультурного многообразия народов России, обеспечению гармонизации межэтнических и межконфессиональных отношений». [12, с.69].

Гражданская идентичность представляет собой сложный феномен, который сочетает в себе характеристики личности, предполагающие «восприятие человеком самого себя в единстве со своей страной, населяющими её народами» (Борисенков В.П., Гукаленко О.В., Пустовойтов В.Н., 2018) и её социальное поведение (осознание принадлежности к сообществу граждан того или иного государства, наследования лучших черт и качеств национального характера русских людей и других народов России). [5, с. 47].

Формирование гражданской идентичности студенческой молодёжи является важнейшим направлением воспитания, способствующим не только формированию мировоззренческого ядра личности, но и обеспечивающих её жизнедеятельность в условиях общества.

Согласимся с позицией ряда учёных Л.П. Карпушиной, И.В. Кожанова, Н.П. Петровой, отмечающих важную роль в формировании гражданской идентичности личности молодого человека этнопедагогического потенциала. $[10,12]$. В этом контексте задачей нашего исследования является выявление сущности феномена «этнопедагогический потенциал региона» и определение его возможностей в процессе формирования гражданской идентичности студентов классического университета Карачаево-Черкесской республики. Значимость этой проблемы возрастает ещё и потому, что в 1994 году был издан Указ Президента Российской Федерации «О мерах по реабилитации карачаевского народа и государственной поддержке его возрождения и развития» (№154 от 30 мая 1994 г.). В этом Указе перед органами 
государственной власти была поставлена задача: содействовать возрождению духовного и культурного наследия карачаевского народа. [9, с. 307].

Следует отметить, что Карачаево-Черкесская Республика является многонациональной. В ней проживают представители разных национальностей: карачаевцы, черкесы, абазины, адыги, русские и др. По мнению В.П. Тоидиса, лидерство занимает карачаевский этнос. [15, с.215]. Этим и обусловлено то, что мы в нашем исследовании сосредоточили внимание на исследовании этнопедагогических особенностей карачаевского этноса.

Особенности Республики определены в исследовании Н.С. Уртенова. Эти особенности включают следующее: ограниченность территориального пространства; высокая плотность населения; высокий прирост населения, отличный от среднего общероссийского; интенсивные миграционные процессы; обострённость межконфессионального и межэтнического взаимодействия; тенденция к «суверенизации»; приспособленность каждого этноса к условиям среды обитания и его гармонизации с природной средой; проявление национальных культур в добре, справедливости, долге, совести, чести, патриотизме, скромности, умеренности, выносливости, дружелюбии; уважительное отношение к соседним народам и их культурам, к труду и людям труда; рост национально-этнического сознания и национальных чувств в условиях этносоциальной напряжённости и военных конфликтов на территориях; повышение роли родных языков в образовании, наряду с национально - русским развивается и русско-национальное двуязычие; повышение значимости религии в обществе, усиление внимания к национальным педагогическим традициям, полиязыковая среда. [16, с. 44].

На наш взгляд, выявленные учёным особенности региона следует учитывать не только в процессе подготовки педагогов, но и других специалистов. В этом контексте нам кажется значимой мысль Х.-Х.М. Батчаевой: «Познание народом своей истории, культуры, традиций, обычаев помогают осознать себя как этнокультурное единство, определить своё место в окружающем мире, свои отличительные особенности и интересы... Освоение истории своего народа способствует пониманию и формированию национального достоинства и оценочных отношений к достоинству других народов». [1, с.93].

Предпримем попытку определения содержательных характеристик феномена «этнопедагогический потенциал региона» с педагогической точки зрения. Структура исследуемого феномена представляет собой синтез нескольких понятий: «этнопедагогика», «потенциал» и «регион».

Рассмотрим содержание каждого из перечисленных составляющих. Исходным понятием для выявления этнопедагогических основ в регионе является понятие «этнопедагогика». Данное понятие имеет богатые традиции, в основе которой лежит культурологическая концепция. Эту концепцию создал Д.С. Лихачёв в 80-е годы XX века. Центральным ядром этой концепции является культура, которую учёный трактовал не только как сумму нравственных ориентиров, знаний и профессиональных навыков, но и как историческую память, как творческую подготовку культуры будущего на основе прошлого и настоящего.

Термин «этнопедагогика» введён Г.Н. Волковым. С точки зрения учёного, этнопедагогика - это «педагогика всеобщей мудрости воспитания, ибо её естественное назначение - постоянное инициирование многостороннего диалога культур... Этнопедагогика - это глобальная педагогика она открывает путь к сердцам людей и народов: чтобы узнать народ, надо знать его традиционную систему воспитания. Поэтому она сплачивает, объединяет народы».

В педагогическом словаре под редакцией Г.М. Коджаспировой, А.Ю. Коджаспирова даётся трактование понятия «этнопедагогика».

Этнопедагогика - наука, предметом изучения которой является народная педагогика, закономерности становления и развития традиционных культур воспитания под воздействием социальных, экономических и других факторов и способы их отражения и функционирования в современной воспитательной системе. [11, с.170].

А.Б. Панькин опрделяет этнопедагогику как народную педагогику; совокупность целей, задач, путей и средств воспитания и обучения, педагогических навыков и приёмов, применяемых в целях привития воспитуемому качеств, соответствующих сложившимся традициям и автостереотипам; составная и неотъемлемая часть общей культуры народа. [14, с.259].

Обобщая все перечисленные определения, выделим общее, что содержится в них. Во-первых, этнопедагогика - это «народная педагогика» (Г.Н. Волков). Во-вторых, это составная часть общей культуры народа. (А.Б. Панькин).

Как отмечалось выше, важной составляющей исследуемого феномена является понятие «регион». Данное понятие активно используется в научной и методической литературе с 90-х годов XX века. Обусловлено это введением национально-регионального компонента на всех уровнях образования (дошкольный, школьный, вузовский).

В научной литературе понятие «регион» рассматривается с различных позиций: социальной, экономиче- 
ской, естественно-исторической и культурной. В словаре профессионального образования под редакцией С.М. Вишняковой данное понятие рассматривается в двух ракурсах: во-первых, как «область, район, территория, часть страны, отличающиеся совокупностью естественных или исторически сложившихся экономико-географических условий и национального состава населения; во-вторых, как «группа близлежащих стран, представляющая собой отдельный экономико-географический район, обладающий общими признаками, отличающие этот район от других районов». [6, с. 278-279].

Нам близко иное рассмотрение понятия «регион»социокультурное. (Т.Л. Божинская). С этой точки зрения в социокультурной составляющей понятия «регион» учёный выделяет следующие детерминанты:

1) большинство действующих в социальной системе факторов представляют собой специфические человеческие способы деятельности, т.е. феномены культуры; 2) все факторы действующие в обществе или воздействующие на него (в том числе природные), даже в тех исторических ситуациях, когда они выходят на первый план, опосредованы общественной психологией. [2, с.17].

В аналогичном ракурсе рассматривает «регион», «регионализацию» Бондаревская Е.В. В понимании учёного это «ориентация на отражение в содержании и воспитании исторического прошлого и настоящего, культурного и социального своеобразия, геополитических, экономических, демографических и других особенностей региона (части страны, округа, области, крупного города, района), потребностей его развития, сохранения средствами образования региональных ценностей культуры, ментальных черт жителей региона». [3, с.480].

Таким образом, регион - это прежде всего люди, проживающие на его территории и образующие определённую историко-культурную общность с присущим только им складом характера, укладом жизни.

Следующая составная часть, входящая в исследуемое понятие - это «потенциал». В педагогической научной литературе данное понятие используется чаще всего в таких сочетаниях: интеллектуальный потенциал педагога (учащегося, студента, преподавателя), творческий потенциал педагогического коллектива, педагогический потенциал, духовный потенциал и т.д. Однако в педагогических словарях это понятие не трактуется.

В словаре С.И. Ожегова потенциал рассматривается в двух значениях: 1) как физическая величина, характеризующая силовое поле в данной точке; 2) как степень мощности в каком-нибудь отношении, совокупность средств необходимых для чего-нибудь. [13, с. 493]. В контексте нашего исследования нам близко второе значе- ние. В исследовании мы рассматриваем феномен потенциал как совокупность этнопедагогических средств для повышения эффективности процесса формирования гражданской идентичности студентов классического университета.

Согласимся с определением понятия «потенциал», приведённого в исследовании Т.Л. Божинской. Учёный рассматривает потенциал как средство, запасы, источники, которые имеются в наличии и могут быть мобилизованы, приведены в действие, использованы для достижения целей, осуществления планов, решения каких-либо задач; как возможности отдельного лица, общества, государств в определённой области. [2, с.27].

В нашем представлении потенциал - это не использованные возможности в исследуемом направлении педагогической деятельности.

Разделяем позицию Т.Л. Божинской и в том, что потенциал, как проблема для современной России должен разрабатываться в рамках региона, так как его специфику и возможности определяют социальная активность населения, культура, интеллектуальная ценность, нравственность населения данного региона, которые детерминируют возможности получения социально значимых результатов в различных сферах жизнедеятельности, т.е. оказывают непосредственное влияние на формирование потенциала личности. [2, с.15]. В контексте нашего исследования речь идёт об этнопедагогическом потенциале и возможностях его использования в процессе формирования гражданской идентичности студентов.

С точки зрения структуры - это понятие многоаспектное и представляет собой совокупность свойств и качеств, присущих этносу определённой территории, который имеет общую культуру и говорит на одном языке основной нации россиян. В данном определении заложена одна из важнейших сущностных характеристик этнопедагогического потенциала региона - это черты характера основной нации региона, т.е. менталитета. В исследовании - это карачаевцы и их ментальность.

А.Б. Панькин под ментальностью понимает, свойственный данному этносу склад мышления. [13, с.258]. В этом определении, на наш взгляд, раскрывается лишь одна сторона менталитета - склад мышления. Гораздо шире рассматривается ментальность в исследовании М.А. Шиловой Н.И. Малиновской. Учёные включают в это понятие и черты национального характера, под которыми ими понимается «совокупность объективных, исторически сложившихся социально-психологических особенностей духовного облика народа, проявляющихся через отношения к вечным общечеловеческим ценностям в свойственных его представителям в традиционных формах поведения и существующих в объекти- 
визированных формах общественного сознания: языке, нормах, ценностях и произведениях народной культуры и образе жизни». [18, с.25].

В своём исследовании мы придерживаемся понимания менталитета, раскрытого в работах Е.В. Бондаревской. Учёный в менталитет вкладывает следующее содержание: «... система фундаментальных ценностей, культурных традиций, норм поведения, которая явным и неявным путём, передаваясь из поколения в поколение, стала основой формирования национального образа жизни, национального видения мира. Если менталитет - понятие, характеризующее образ жизни нации, то ментальность отражает отношение к менталитету отдельных людей, проявления его в их бытии, привычных формах поведения и отношений». [9, с. 54].

Что касается черт характера, характеризующих карачаевцев, то в работах X.-Х.-М. Батчаевой и М.Б. Гуртуевой выделены эти черты. [1, 8]. К таким чертам карачаевцев учёные относят чувство собственного достоинства, гордость, честность, нравственную чистоту, обходительность, гостеприимство и выносливость. [8, с.15]. Нравственная чистота и выносливость помогли карачаевцам не только выжить в годы депортации, но и не сломаться: получать образование, трудиться и вместе с обществом подниматься на новый уровень в профессиональной и общественной деятельности. Особенности национального характера ведущего этноса республики учитываются в образовательной деятельности классического университета. О достижениях выпускников вуза повествуется на страницах журнала «Эльбрусоид», с которым университет плодотворно сотрудничает. В университете проводятся Дни Эльбрусоида, встречи с выдающимися людьми республики, которые для молодых людей являются эталонами действия, мысли и чувства.

Другой сущностной характеристикой этнопедагогического потенциала региона являются национальные (этнические) традиции. Согласимся с определением традиций, данных С.К. Бондыревой, Д.В. Колесовым. В их представлении традиции являются «способом накопления жизненно важного и общественно значимого опыта» [4, с. 3]. А.Б. Панькин конкретизирует традиции: «Они аккумулируют, передают и воспроизводят исторический этнокультурный опыт этнических общностей». [14, с. 258]. Такие традиции как гостеприимство, почитание старших воздействуют на формирование таких качеств, как обходительность и уважение. Однако во многих исследованиях учёных университета отмечается, что молодое поколение, живущее в городах республики, плохо владеют родным языком, не знают традиций своего народа. Для того чтобы исправить ситуацию по инициативе выпускника университета - заслуженного учителя КарачаевоЧеркесии 3. Бостановой создан социально-досуговый центр «Очаг добра», в котором проводятся занятия со взрослыми и детьми по родному языку, мероприятия по использованию традиций и правил этикета, принятым у карачаевцев, в современных условиях.

Следующей характеристикой этнопедагогического потенциала региона является наличие «компонентов материальной, духовной и соционормативной культуры, сложившихся в процессе формирования и развития этноса и являющихся для него специфическими». (А.Б. Панькин, 2006).

Разделяем позицию А.Б. Панькина, заключающуюся в том, что этнопедагогическая культура тесно взаимосвязана с языком. Учёный отмечает, что «язык относится к элементам культуры, функциональная значимость которых выражена наиболее отчётливо, - это общественно-исторический продукт, в котором находят отражение культура, система социальных отношений, традиций». [14, c.98-99].

Языковую систему этноса, под которой нами понимается система знаков, средств и правил говорения, мы считаем важной характеристикой этнопедагогического потенциала региона. В этом контексте карачаевский язык, язык самой многочисленной группы народов Республики, оказывает влияние на речь учителя, журналиста, юриста, а речь является формой существования языка, его воплощения, реализации.

3.Б. Цаллагова обращает внимание и на такую языковую особенность языков народов Северного Кавказа, как афористичность речи. С точки зрения учёного, афористика «несёт воспитательные идеи и имеет воспитательное значение, она содержит и определённый воспитательный императив». [17, с.269].

Аналогичной точки зрения придерживается М.Б. Гуртуева, которая считает, что «произведения карачаевобалкарского фольклора не только раскрывают картину духовной жизни общества «таукула», то поныне являются важнейшим средством формирования высоконравственной личности. Столетиями фольклор нёс на себе функцию неписанного учебника жизни. И сегодня он является неотъемлемой частью учебно-воспитательной программы современной школы... Пословицы и поговорки, изречения сказочных, легендарных героев, слова из народных песен прочно вошли в обыденную речь карачаевцев и балкарцев, так как они наиболее полно отражают их образ жизни». [8, с.8]. Языковые особенности карачаевского этноса находят отражение в публикациях, курсовых и дипломных работах студентов разных направлений подготовки.

Этнопедагогический потенциал региона можно характеризовать и применительно к месту локализации. В данном случае потенциал региона анализируется при- 
менительно к Карачаево-Черкесской Республике.

Теоретический анализ позволил сформировать собственное понимание этнопедагогического потенциала региона. Во-первых, этнопедагогический потенциал представляет собой синтез понятий: этнопедагогика, потенциал, регион. Во-вторых, этнопедагогический потенциал региона определяется национально-специфическими особенностями, обусловленными природными, социальными и территориальными условиями. В-третьих, этнопедагогический потенциал региона характеризуется совокупностью признаков, которые необходимо учитывать. Это: ментальные черты жителей региона, национальные традиции, региональные ценности культуры, языковая система этноса, пространственная локализация.

Выявленные в ходе теоретического анализа характеристики этнопедагогического потенциала региона учитываются в проекте, разработанном в Карачаево-Черкесском государственном университете им. У.Д. Алиева по теме: «Формирование гражданской идентичности студентов на основе использования этнопедагогического потенциала региона». В этом проекте используются как традиционные формы работы со студентами (студенческий клуб, видеопутешествия, участие в акциях, посвящённых различным аспектам регионоведения) так и нетрадиционные (конкурсы проектов, форумы студентов и волонтёрские отряды, педагогические экспедиции и т.д.).

Резюмируя вышеизложенное, отметим, что в процессе формирования гражданской идентичности студентов важно учитывать этнопедагогические особенности региона его признаки, что предполагает наличие у студенTOB:

- знаний национально-психологических особенностей карачаевского этноса;

- знаний национальных обычаев, обрядов и традиционной культуры народа;

- знаний языковых особенностей ведущего этноса;

- наличие мотивации реализовывать полученные знания, этнокультурный диалог.

\section{ЛИТЕРАТУРА}

1. Батчаева Х.-Х.М. Традиционная педагогическая культура карачаевского народа (история, теория, практика). - Казань: Изд-во Казан. ун-та, $2002 .-417$ с.

2. Божинская Т.Л. Педагогический потенциал региональной культуры в современном российском образовании: автореф. дисс. . . канд.фил.наук. - Краснодар, 2010. - 32 c.

3. Бондаревская Е.В. Воспитание как встреча с личностью (Избранные педагогические труды в двух томах). - Т.ІІ - Ростов н/Д: Изд-во РГПУ, 2006. - 504 с.

4. Бондырева С.К., Колесов Д.В. Традиции. Стабильность и преемственность в жизни общества:Учебн. пособие. - М.: Изд-во Московского псих.-соц. института; Воронеж: Изд-во НПО «МОДЭК», 2007. - 280 с.

5. Борисенков В.П., Гукаленко О.В. Пустовойтов В.Н. Поликультурное воспитательное пространство вуза как среда формирования гражданственности и патриотизма. //Педагогика, 2018. - №2. - с.44-53.

6. Вишнякова С.М. Профессиональное образование. Словарь. Ключевые понятия, термины, актуальная лексика. - М.: НМЦСПО, 1999. - 538 с.

7. Волков Г.Н. Этнопедагогика - педагогика национального спасения. - Элиста, 2001. - 304 с.

8. Гуртуева М.Б. Этнопедагогика карачаево-балкарского народа. - Нальчик: Эльбрус, 1997. - 256 с.

9. Депортация карачаевцев. Документы рассказывают. - Черкесск, 1995. - 344 с.

10. Карпушина Л.П. Этнокультурный подход как фактор социализации подрастающих поколений. //Актуальные проблемы современных педагогических исследований: Сб. науч.статей Всерос. науч.-практ.конф. - СПб, 2016.

11. Коджаспирова Г.М., Коджаспиров А.Ю. Педагогический словарь. - М.: Изд-во центр «Академия», 2001. - 176 с.

12. Кожанов И.В., Петрова Н.П. Этнокультурные педагогические технологии в формировании гражданской идентичности личности. //Педагогика, 2017. №7. - c.68-75.

13. Ожегов С.И. Словарь русского языка. /Под ред. Н.Ю. Шведовой. - М.: Рус. яз, 1986. - 797 с.

14. Панькин А.Б. Формирование этнокультурной личности. - М.: Изд-во психолого-социального института; Воронеж: Изд-во НПО «МОДЭК», $2006 .-280$ с.

15. Тоидис В.П. 0 некоторых проблемах этничности в КЧР. //Горские общества Кавказа: проблемы социокультурного, политического, исторического развития: Материалы Всерос. научной конференции, посвящённой 180-летию присоединения Карачая к России: часть III - Карачаевск: КЧГУ, 2008. C. $210-220$.

16. Уртенов Н.С. Особенности подготовки педагогов для работы в поликультурном регионе. //Система многоуровневого образования: современные подходы, тенденции развития и региональные аспекты. Материалы международной заочной научн.-практ. конференции. - Карачаевск: КЧГУ, 2012. - с. 43-47.

17. Цаллагова 3.Б. Этнокультурное наследие народов Кавказа как содержательная основа формирования толерантных межнациональных отношений. // Горские общества Кавказа. Проблемы социокультурного, политического, исторического развития. Часть ІІ. - Карачаевск: КЧГУ, 2008. - с. 263-272.

18. Шилова М.И., Малиновская Н.И. Черты национального характера: российский вариант. //Педагогика, 2002. - №8. - с.24-35.

( Савинова Людмила Федоровна (savinova.lf@mail.ru), Хасанова Марина Османовна (marina.khasanova@mail.ru). 